\title{
PRODUÇÃO E QUALIDADE DOS FRUTOS DE PESSEGUEIRO E NECTARINEIRA EM CLIMA SUBTROPICAL DO ESTADO DE SÃO PAULO ${ }^{1}$
}

\author{
SARITA LEONEL ${ }^{2}$, CAROLINE GERALDI PIEROZZI $^{3}$, MARCO ANTONIO TECCHIO $^{4}$
}

RESUMO - Tendo em vista que o conhecimento do comportamento de uma cultura, em determinada região, determina o sucesso da produção, a qualidade do produto final e a garantia de aceitação pelo mercado consumidor, o presente trabalho teve como objetivo avaliar a produção e as características físicas e físicoquímicas de frutos de cultivares de pessegueiro e nectarineira, cultivados ou não tradicionalmente em São Paulo, mas que possam vir a apresentar uma opção de diversificação aos fruticultores do município de Botucatu-SP, e regiões climáticas semelhantes. O experimento foi realizado durante três ciclos agrícolas: 2006/2007, 2007/2008 e 2008/2009, na Faculdade de Ciências Agronômicas, UNESP, Botucatu-SP. O clima da região é do tipo mesotérmico, Cwa, ou seja, subtropical úmido com chuvas no verão e seca no inverno. As cultivares de pessegueiro avaliadas foram: Turmalina, Cascata 968, Cascata 848, Cascata 587, Conserva 693, Precocinho, Diamante Mejorado, Oro Azteca, CP-9553CYN e Tropic Beauty. A cultivar de nectarineira avaliada foi 'Sun Blaze'. Foram avaliadas características de produção e qualidade dos frutos. Os resultados obtidos permitiram concluir que a cultivar Turmalina foi a mais produtiva. As cultivares Cascata 968 e Diamante Mejorado apresentaram o maior teor de sólidos solúveis, e as cultivares Cascata 587 e CP 9553 CYN, a maior relação sólidos solúveis/acidez titulável.

Termos para indexação: Prunus persica var. nucipersica, Prunus persica var. vulgaris, clima, desempenho agronômico.

\section{PRODUCTION AND QUALITY OF PEACH AND NECTARINE FRUITS UNDER SUBTROPICAL CLIMATE OF THE STATE OF SÃO PAULO}

\begin{abstract}
The behavior of peaches in a certain region determines the production success, the final product quality and the guaranteed acceptance by the consumer market. The present study aimed to evaluate the production and quality of fruits from cultivars of peach and nectarine trees, cultivated or not, with a purpose to obtain more options of fruits cultivars in Botucatu, State of São Paulo, Brazil, and regions with the same climate conditions. The experiment was carried out during three crop cycles, 2006/2007, 2007/2008 and 2008/2009, at the School of Agronomical Sciences, UNESP, Botucatu campus. The predominant climate in the region is mesothermic, Cwa, subtropical humidity, with rainfall in the summer and drought in the winter. The evaluated peach tree cultivars were: Turmalina, Cascata 968, Cascata 848, Cascata 587, Conserva 693, Precocinho, Diamante Mejorado, Oro Azteca, CP-9553 CYN and Tropic Beauty. The evaluated cultivar of nectarine was Sun Blaze. Yield and fruit quality characteristics were assessed. The obtained results indicated that the cultivar Turmalina was the most productive. The cultivars Cascata 968 and Diamante Mejorado had the highest soluble solid content and the cultivars Cascata 587 and CP 9553 CYN presented the highest soluble solid/acidity titratable.
\end{abstract}

Index terms: Prunus persica var. nucipersica, Prunus persica var. vulgaris, climate, agronomic characteristics.

\footnotetext{
'(Trabalho 055-10). Recebido em: 22-02-2010. Aceito para publicação em: 01-12-2010.

${ }^{2}$ UNESP. Professor Adjunto. Faculdade de Ciências Agronômicas. Departamento de Produção Vegetal. Caixa Postal 237, CEP 18610.307, Botucatu-SP. Trabalho financiado pela FAPESP. E-mail: sarinel@fca.unesp.br

${ }^{3}$ UNESP. Faculdade de Ciências Agronômicas. Departamento de Produção Vegetal. Caixa Postal 237, CEP 18610.307, Botucatu-SP. E-mail: carolpierozzi@hotmail.com Bolsista de Iniciação Científica da FAPESP. Processo nº 07/56368-5 R.

${ }^{4}$ Centro Avançado de Pesquisa Tecnológica do Agronegócio de Frutas - Instituto Agronômico de Campinas - CEP 13214-820 Jundiaí-SP. Email: tecchio@iac.sp.gov.br
} 


\section{INTRODUÇÃO}

As culturas de pêssego, nectarina e ameixa, no Estado de São Paulo, são responsáveis por uma considerável porcentagem da produção nacional, sendo o mesmo o segundo principal Estado em área de cultivo, com cerca de 2.800 hectares, voltados na grande maioria para o mercado de frutas ao natural (ANUÁRIO BRASILEIRO DA FRUTICULTURA, 2010). De acordo com Barbosa et al. (2003), o pessegueiro é a segunda planta de clima temperado mais cultivada no Estado de São Paulo, incluindo-se a nectarineira, que equivale a $12 \%$ da persicultura paulista. No município de Guapiara, na região de Itapeva, encontra-se o principal polo de cultivo do pessegueiro. Em relação à nectarineira, Paranapanema é o principal município produtor, seguido por Guapiara.

A fruticultura de clima temperado paulista tem-se caracterizado, nas últimas décadas, por significativa ampliação regional e varietal. Em moldes comerciais, a fruticultura paulista deixou de ser praticada somente em áreas serranas e em municípios próximos da Capital, deslocando-se para outras regiões subtropicais e tropicais do interior, muitas vezes desprovidas de temperaturas hibernais baixas (BARBOSA et al., 2003). Verifica-se que, em consequência do melhoramento genético, a expansão da fruticultura de clima temperado vem avançando progressivamente até o Planalto Paulista, com sucesso econômico.

Segundo Pereira et al. (2002) e Sacarpare Filho et al. (2003), muitas cultivares de pêssegueiro e nectarineira vêm sendo cultivadas em regiões tropicais e subtropicais do Estado de São Paulo, com índices térmicos entre 40 e 80 horas (abaixo de 7 ${ }^{\circ} \mathrm{C}$ ) ou 600 e 800 horas (abaixo de $13{ }^{\circ} \mathrm{C}$ ), em áreas próximas a Jaboticabal, Campinas, Tietê, Botucatu e até mesmo em Bauru.

O conhecimento da capacidade de adaptação das cultivares de pessegueiro a determinada região é muito importante, pois através dele é possível se tomarem decisões como época e tipos de poda a serem realizadas, necessidade de desfolha e irrigação, uso de reguladores de crescimento vegetais e, com isso, possibilitar que a cultura expresse seu máximo potencial produtivo.

Nesse contexto, com vistas à seleção de cultivares para regiões de clima subtropical, com exigência entre 0-200 horas de frio, no Estado de São Paulo, Barbosa et al. (2007) avaliaram os seguintes genótipos: Talismã, Néctar, Cristal, Canário, Joia 1 e 2, Centenário, Petisco 2, Dourado 1, Natal, Delicioso Precoce, Joia 4, Aurora 1, Tutu, Catita, Joia 3, Colibri, Brasão, Dourado 2, Joia 5, Supermel, Ouromel 2, Petisco, Arlequim, Régis, Real, Biuti, Tropical 1 e 2, Aurora 2, Doçura 2, Bolão, Momo e Douradão. Os autores concluíram que o período produtivo dessas cultivares estendeu-se de agosto a fevereiro, cerca de 80 a 180 dias após o pleno florescimento. Os autores concluíram que as cultivares apresentadas têm sido aceitas pelos persicultores e consumidores, permitindo a indicação da possibilidade do cultivo em regiões subtropicais.

O valor da comercialização do pêssego é reflexo da demanda e de sua apreciação pelo consumidor. A compreensão da diferença de valor entre os frutos das diferentes cultivares e da sua relação com as características que determinam o gosto do fruto, torna possível o estabelecimento de uma estratégia de comercialização, visando ao aumento no consumo e na receita do produtor, além de dar subsídios aos programas de melhoramento genético (ALMEIDA; DURIGAN, 2006).

O potencial econômico do cultivo de pessegueiros e nectarineiras no Estado de São Paulo apresenta como grande vantagem a colheita antecipada dos frutos, quando comparada não só com as principais regiões produtoras brasileiras, mas também com a maioria dos países localizados no Hemisfério Sul, como Chile, Argentina, Uruguai e África do Sul, adicionada à possibilidade de diversificação de cultivares mais adaptadas ao clima subtropical, cuja adoção pelos produtores poderia possibilitar aumento na renda e na sazonalidade da oferta do produto. Assim, no presente trabalho, teve-se como objetivo avaliar a produção e as características físicas e físico-químicas de frutos de cultivares de pessegueiro e nectarineira, tradicionalmente cultivadas ou não em São Paulo, mas que possam vir a apresentar uma opção de diversificação aos fruticultores do município de Botucatu-SP, e regiões climáticas semelhantes. 


\section{MATERIAL E MÉTODOS}

O experimento foi realizado na Faculdade de Ciências Agronômicas, FCA/UNESP, Botucatu-SP, situado a $22^{\circ} 51^{\prime} 55^{\prime \prime} \mathrm{S}, 48^{\circ} 27^{\prime} 22^{\prime \prime} \mathrm{O}$ e a $810 \mathrm{~m}$ de altitude. O clima da região, segundo a classificação de Köeppen, é do tipo mesotérmico, Cwa, ou seja, subtropical úmido com estiagem no período de inverno e com chuvas de novembro a abril, sendo a precipitação média anual de $1.433 \mathrm{~mm}$. A umidade relativa do ar é de $71 \%$, com temperatura média anual de $19,3{ }^{\circ} \mathrm{C}$ (CUNHA et al., 1999). Os dados de temperaturas médias, máximas e mínimas, bem como de precipitação pluvial da área experimental foram fornecidos pelo Setor de Ciências Ambientais do Departamento de Recursos Naturais da FCA/ UNESP e são apresentados na Figura 1 . O solo da área é classificado como Nitossolo Vermelho, segundo os critérios da EMBRAPA (1999).

O delineamento experimental adotado foi o inteiramente casualizado, com parcelas subdivididas, cinco repetições e três plantas úteis por parcela experimental, sendo que as parcelas corresponderam às 10 cultivares de pessegueiros e 1 de nectarineira, e as subparcelas aos 3 anos de avaliação, correspondentes aos ciclos agrícolas de 2006/2007, 2007/2008 e 2008/2009. Em julho de 2006, as plantas da área experimental estavam com 4 anos de idade, cultivadas no espaçamento de $6,0 \mathrm{~m}$ entre linhas e 4,0 m entre plantas, em área de sequeiro. O porta-enxerto utilizado para todas as cultivarescopa foi o 'Okinawa'.

Durante todo o período de condução do experimento, foram realizadas amostragens de solo na área experimental para verificar a necessidade de adubação e correção do solo, além da realização de práticas culturais e fitossanitárias, para garantir o desenvolvimento das plantas, seguindo as recomendações técnicas da cultura (PEREIRA et al., 2002). As podas de frutificação foram realizadas no mês de julho dos anos de 2006, 2007 e 2008. Foi adotado o critério de deixar que as plantas tivessem o florescimento e a frutificação espontânea, sem a utilização de regulador vegetal para a quebra da dormência. A necessidade e a intensidade do raleio de frutos foram determinadas anualmente, sendo adotado o seguinte critério: a quantidade de frutos nos ramos foi diminuída em três vezes, para possibilitar melhor crescimento dos frutos restantes (BARBOSA et al., 1997).

Foram avaliadas 3 cultivares de pessegueiros oriundas do México: 'CP-9553 CYN', 'Oro Azteca' e 'Diamante Mejorado'; 2 cultivares desenvolvidas pela Embrapa-CNPCT (Centro de Pesquisa de Clima Temperado), atual Embrapa Clima Temperado de Pelotas-RS: 'Precocinho' e 'Turmalina'; 4 seleções de pessegueiros também desenvolvidas pelo mesmo Centro de Pesquisa da Embrapa: 'Cascata 968', 'Cascata 848', 'Cascata 587' e 'Conserva 693'; uma cultivar de pessegueiro vinda da Flórida: 'Tropic Beauty', e uma cultivar de nectarineira, também oriunda da Flórida: 'Sun Blaze', cujas principais características reportadas na literatura são descritas resumidamente a seguir.

A cultivar CP-9553 CYN possui frutos redondos, com ligeira sutura e $95 \%$ de coloração externa vermelha, com polpa amarela não fundente. $\mathrm{O}$ fruto apresenta peso médio de $120 \mathrm{~g}$. Necessita de 225 horas de frio abaixo de $7,2{ }^{\circ} \mathrm{C}$. A cultivar Diamante Mejorado apresenta frutos redondos, com $15 \%$ de coloração vermelha na epiderme e polpa amarela não fundente. $\mathrm{O}$ fruto apresenta peso médio de 110 g. Necessita de 250 horas de frio abaixo de $7,2{ }^{\circ} \mathrm{C}$. A cultivar Oro Azteca apresenta a epiderme amarelo-avermelhada (acima de 50\% amarelo), com polpa amarela e teores médios de: acidez, 0,89 $\mathrm{g}$ ácido cítrico $100 \mathrm{~g}$ de polpa ${ }^{-1}$, sólidos solúveis, $10,6{ }^{\circ}$ Brix e ratio (SS/AT) de 11,91 (MARODIN et al., 2008).

Precocinho é uma cultivar de pessegueiro para indústria ou com dupla finalidade. Os frutos são de forma redondo-ovalada, apresentando sutura levemente desenvolvida. São de tamanho médio (diâmetro entre 4,7 e $5,7 \mathrm{~cm}$ ), com peso médio variando entre 82 e 95g. A película é amarela. A polpa é amarela, firme e aderente ao caroço, e o sabor é doce-ácido (RASEIRA; NAKASU, 1998).

A cultivar Turmalina é utilizada para indústria ou com dupla finalidade, os frutos têm formato redondo cônico, sem ponta. A película e a polpa são amarelo-ouro, sendo esta última firme e aderente ao caroço. O tamanho dos frutos é do tipo I e II para indústria, com peso médio, em geral, superior a $100 \mathrm{~g}$, mas em alguns anos, entre 89 e 90 g. O diâmetro equatorial dos frutos atinge facilmente 5,8 e $6,1 \mathrm{~cm}$. O sabor é doce-ácido (RASEIRA; NAKASU, 1998).

As seleções de pessegueiro pertencentes à Embrapa (CPACT): Cascata 968, Cascata 848, Cascata 587 e Conserva 693 estão em testes com produtores e instituições, e não se encontram ainda liberadas para plantio. Por isso, dispõe-se de poucos dados sobre o desempenho dessas seleções. A seleção Cascata 587 possui frutos de polpa branca com 
epiderme vermelha (mais de $80 \%$ ), e as seleções Cascata 968 e 848 e Conserva 693 apresentam frutos de polpa amarela.

A cultivar Tropic Beauty possui frutos de polpa amarela, caroço preso, epiderme vermelha, textura firme e alta acidez (BARBOSA et al., 1997). A nectarineira 'Sun Blaze' é produtiva, e os frutos apresentam diâmetro variando entre 5,3 e 6,5 cm. A película é amarelo-esverdeada com $95 \%$ de vermelho. A polpa é amarela, fundente, aderente ao caroço e de firmeza média. O sabor tende mais para ácido, não satisfazendo plenamente as preferências do mercado nacional. No entanto, em virtude da época de colheita, do tamanho e da aparência, é aceita no mercado (RASEIRA; NAKASU, 1998).

A colheita foi realizada quando os frutos atingiram o ponto de maturação fisiológica, através da cor da casca, que correspondeu ao final do mês de setembro até meados de dezembro dos três ciclos agrícolas, para todas as cultivares avaliadas.

Após a colheita, foi calculada a produção média por planta $\left(\mathrm{kg} \mathrm{planta}^{-1}\right)$, a qual foi obtida pelo produto do número médio de frutos e respectivo peso médio. A produtividade $\left(\mathrm{kg} \mathrm{ha}^{-1}\right)$ foi determinada considerando-se um estande de 416 plantas $/ \mathrm{ha}^{-1}$.

Posteriormente, os frutos foram levados ao Laboratório de Frutas e Hortaliças do Departamento de Gestão e Tecnologia Agroindustrial, onde foram efetuadas as avaliações físicas e físico-químicas. Foram avaliados 50 frutos de cada cultivar, nos quais foram mensuradas características físicas: diâmetros transversal e longitudinal ( $\mathrm{mm}$ ), com o auxílio de um paquímetro digital (digimess $300 \mathrm{~mm}$ ). Firmeza da polpa: medida nos frutos inteiros com casca, em 3 pontos diferentes, utilizando o texturômetro Stevens - LFRA Texture Analyser, determinada pela pressão necessária para fazer uma ponta de prova de $6 \mathrm{~mm}$ de diâmetro penetrar $20 \mathrm{~mm}$ no fruto, sendo expressa em $\mathrm{gf}^{-2}$; teor de sólidos solúveis, determinado por refratometria direta em ${ }^{\circ}$ Brix (INSTITUTO ADOLFO LUTZ, 1985); acidez titulável, obtida por meio da titulação de $5 \mathrm{~g}$ de polpa homogeneizada e diluída para $100 \mathrm{ml}$ de água destilada, com solução padronizada de hidróxido de sódio a $0,1 \mathrm{M}$, tendo como indicador a fenolftaleína, conforme recomendação do Instituto Adolfo Lutz (1985), e expressa em $\mathrm{g}$ de ácido cítrico $100 \mathrm{~g}^{-1} ; \mathrm{pH}$, mensurado no extrato da polpa homogeneizada, utilizando-se do potenciômetro da marca Digimed DMPH-2 (INSTITUTO ADOLFO LUTZ, 1985); Relação sólidos solúveis/ acidez titulável; açúcares redutores e açúcares solúveis totais, pela metodologia descrita por Somogy e adaptada por Nelson (1944). O aparelho utlizado foi o espectrofotômetro Micronal B 382, sendo a leitura a $535 \mathrm{~nm}$, e os resultados expressos em g $100 \mathrm{~g}^{-1}$.

Com os resultados obtidos, determinou-se a média de cada cultivar para as características avaliadas. Os resultados foram submetidos à análise de variância, e as médias, comparadas pelo teste de Tukey, ao nível de $5 \%$ de probabilidade.

\section{RESULTADOS E DISCUSSÃO}

Observou-se que todas as cultivares avaliadas apresentaram florescimento espontâneo nos três ciclos agrícolas de avaliação, apesar de o mesmo não ter sido quantificado. Foi possível verificar que o ano de 2007 apresentou temperaturas mais favoráveis para a brotação e o florescimento do pessegueiro e nectarineira, quando comparado com o ano de 2006, e isso refletiu-se nos maiores dados de produção obtidos nos anos de 2007 e 2008, respectivamente, uma vez que o pessegueiro floresce e frutifica nos ramos do ano anterior (Figura 1 e Tabela 1). As cultivares adaptadas e melhoradas para as regiões subtropicais não têm necessidade de acumular muitas horas de frio e brotam facilmente, enquanto as cultivares mais exigentes em número de horas de frio dificilmente brotam após o inverno, em regiões de inverno ameno, como no Estado de São Paulo, pois não conseguem acumular frio suficiente para superação da dormência (BARBOSA et al.,2003).

Os resultados de produtividade obtidos neste trabalho são inferiores às médias obtidas pelos produtores de pêssego e nectarina, mas há de se considerar que o experimento avaliou o florescimento espontâneo das plantas, sem a utilização de regulador vegetal para a quebra da dormência, aliada à constatação de que talvez não estejam sendo comparadas plantas de mesma idade e tamanho. A cultivar Turmalina foi a mais produtiva nos três ciclos de avaliação $(3.583 \mathrm{~kg}$ $\mathrm{ha}^{-1}$ ) e apresentou, em média, frutos com diâmetros longitudinais e transversais de 7,0 e $6,9 \mathrm{~cm}$, respectivamente (Tabela 1), confirmando sua indicação para o uso industrial (NAKASU; RASEIRA, 1999) ou com dupla finalidade. Destacou-se também a seleção Cascata 848, a qual apresentou produtividade semelhante à cultivar Turmalina nos ciclos de 2007 e 2008. Quanto às dimensões dos frutos, a seleção Cascata 587 e as cultivares Tropic Beauty e Sun Blaze apresentaram valores semelhantes à cultivar Turmalina.

Com exceção da seleção Cascata 587, que apresenta polpa branca, todos os genótipos avalia- 
dos apresentam a polpa dos frutos amarela, o que possibilita a utilização industrial. Porém, há de se considerar que, neste caso, a firmeza da polpa é um requisito fundamental. Nessa característica, a média dos três anos de avaliação revelou pequenas variações entre as cultivares (Tabela 2), destacando-se a seleção Cascata 968 (293,0 $\left.\mathrm{gf} \mathrm{cm}^{-2}\right)$, que diferiu das cultivares Precocinho (216,3 $\mathrm{gf} \mathrm{cm}^{-2}$ ) e Cascata 587 $\left(215,3 \mathrm{gf} \mathrm{cm}^{-2}\right)$, por apresentar frutos com maior firmeza da polpa, o que é considerada uma característica importante e favorável. De acordo com Barbosa et al. (1999), para frutos destinados ao consumo ao natural, também é grande a importância comercial dada aos pêssegos firmes e de maior tamanho, que não exijam raleio dos frutos.

As características físicas e químicas reveladas pelos teores de sólidos solúveis, acidez titulável e açúcares, entre outras, são indicadoras das características sensoriais, importantes para o consumo in natura e também para a indústria (CHITARRA; CHITARRA, 2005).

Verificou-se que houve poucas variações nos teores de sólidos solúveis nos frutos das cultivares avaliadas (Tabela 2). Os maiores valores foram observados na seleção Cascata 968 (13,6 Brix) e na cultivar Diamante Mejorado (12,7 Brix), que diferiram dos demais materiais avaliados. Raseira e Nakasu (1998), no Rio Grande do Sul, concluíram que os teores médios de sólidos solúveis para as cultivares Precocinho e Turmalina foram de 8 a $11^{\circ}$ Brix e 10 a $13^{\circ}$ Brix, respectivamente, valores próximos aos mensurados neste trabalho. A cultivar Precocinho apresentou, em média de três anos de avaliação, $11,9^{\circ}$ Brix, e a 'Turmalina' 11, $6^{\circ}$ Brix, o que se enquadra dentro da faixa de caracterização dessas cultivares, mesmo com ensaios sendo realizados em épocas e locais distintos. Com relação às seleções de pessegueiros Cascata, Raseira et al. (2007) relataram teores de sólidos solúveis na faixa de 11 a $16^{\circ}$ Brix, corroborando os resultados do presente trabalho, nos quais o teor de sólidos solúveis para essas seleções variou de 11,6 a $13,6^{\circ}$ Brix.

Para a cultivar Tropic Beauty, os autores mencionaram o valor de $12,9^{\circ}$ Brix, muito próximo a $12,42^{\circ}$ Brix reportado por Costa et al. (2008) para a mesma cultivar, enquanto, no presente trabalho, os valores foram: $11,2^{\circ}$ Brix em 2006, 12,3 ${ }^{\circ}$ Brix em 2007 e $19,6^{\circ}$ Brix em 2008, sendo que o valor mais alto no ano de 2008, provavelmente, deveu-se à ocorrência de temperaturas máximas e médias mais elevadas no período de amadurecimento dos frutos, conforme verificado na Figura 1. Os sólidos solúveis são compostos solúveis em água e importantes na determinação da qualidade do fruto, uma vez que fornecem um indicativo da quantidade de açúcares existentes no fruto, considerando que outros compostos, embora em reduzidas proporções, também fazem parte, como, por exemplo, ácidos, vitaminas, aminoácidos e algumas pectinas.

Os teores médios de açúcares redutores variaram de 1,59 a 2,21\%, sendo os maiores valores obtidos nos materiais de Cascata 969, Cascata 848, Cascata 587, Precocinho, Diamante Mejorado, Oro Azteca e Sunblase. O amadurecimento dos frutos, em geral, conduz à maior doçura, devido ao aumento nos teores de açúcares simples, decorrentes de processos biossintéticos ou degradativos de polissacarídeos presentes nos frutos (GONÇALVES, 1998). O sabor dos frutos corresponde a um balanço entre os constituintes doces e ácidos, frequentemente com pequenas proporções de amargor ou adstringência, devido aos taninos. Chitarra e Carvalho (1985) relataram teores de açúcares redutores em pêssegos variando entre 2,0 a 3,2\%. Para a cultivar Tropic Beauty, Costa et al. (2008) encontraram valores que variaram de 1,51 a $4,49 \%$, conforme o tempo $(0 ; 5 ; 10 ; 15 ; 20$ e 25 dias) e as condições de armazenamento (conservação ambiente e frigorificada) dos frutos .

A diferença entre os açúcares solúveis totais e os redutores são a sacarose e o sorbitol. Oliveira et al. (2001) verificaram que a sacarose foi o açúcar encontrado em maior quantidade em pêssegos maduros, excedendo a quantidade de açúcares redutores (glicose e frutose). De acordo com Esti et al. (1997), os teores de sacarose em pêssegos podem variar de $4,3 \%$ a $9,8 \%$; de glicose de $0,4 \%$ a $2,0 \%$, e os de frutose de $0,4 \%$ a $3,4 \%$. A doçura da sacarose é maior que a da glicose e da frutose. Dessa maneira, as cultivares que apresentassem maior teor de açúcares solúveis totais poderiam ser consideradas mais doces. Contudo, não houve diferenças entre as cultivares avaliadas com relação ao teor de açúcares solúveis totais, havendo apenas diferença entre os anos de avaliação, nos quais o ano de 2007 apresentou o maior valor $(8,9 \%)$, quando comparado com $2006(7,9 \%)$ e $2008(6,8 \%)$ (Tabela 4). Tal fato, possivelmente, possa ser explicado por a precipitação média acumulada ter sido menor em 2007, quando comparada a 2006 e 2008, respectivamente. Pinto e Jorge (2007) citam valores de açúcares solúveis totais em pessegueiro variando de 8,02 a $13,83 \%$ e Costa et al. (2008) reportaram, para a cultivar Tropic Beauty, valores entre 7,17 a $10,57 \%$, conforme o período de armazenamento dos frutos. 
O sabor é um dos componentes mais subjetivos da qualidade das frutas e é resultado da combinação entre as sensações produzidas pelo paladar e pelo olfato. Nos pêssegos, o gosto é composto principalmente pelo teor de açúcares e pela relação deste teor com o de acidez titulável e o sabor, pela combinação do gosto com o olfato, estimulado pelos produtos voláteis (ALMEIDA;DURIGAN, 2006). O principal açúcar do pêssego é a sacarose, seguida da frutose e sorbitol, com os teores variando conforme a cultivar, enquanto os principais ácidos orgânicos são o málico e o cítrico (BALDWIN, 2005).

Os valores obtidos para os teores de acidez titulável indicaram diferenças entre as cultivares, sendo que as seleções Cascata 968 e Conserva 693, a cultivar de pessegueiro Tropic Beauty e a nectarineira 'Sun Blaze' apresentaram os maiores teores de acidez, com variações médias de 0,97 a $0,87 \mathrm{~g}$ ácido cítrico $100 \mathrm{~g} \mathrm{polpa}^{-1}$. Almeida e Durigan (2006) reportaram para a cultivar Tropic Beauty, $0,7 \mathrm{~g}$ ácido cítrico $100 \mathrm{~g} \mathrm{ml} \mathrm{polpa}^{-1}$, sendo essa, de acordo com os autores, a cultivar mais ácida produzida no município de Paranapanema-SP, na safra de 2004. Esses dados são concordantes com os obtidos neste trabalho, no qual a Tropic Beauty apresentou acidez titulável média de $0,88 \mathrm{~g}$ ácido cítrico $100 \mathrm{~g} \mathrm{polpa}^{-1}$. Marodin et al. (2008), avaliando a cultivar mexicana Oro Azteca, em Eldorado do Sul-RS, encontraram valores de acidez titulável de $0,81 \mathrm{~g}$ ácido cítrico $100 \mathrm{~g}$ polpa $^{-1}$, sendo considerada uma cultivar ácida pelos autores. Nas condições edafoclimáticas do presente experimento, a cultivar apresentou valores médios de acidez titulável de $0,68 \mathrm{~g}$ ácido cítrico $100 \mathrm{~g} \mathrm{polpa}^{-1}$, sendo também considerada uma cultivar ácida.

Os ácidos orgânicos são produtos intermediários do metabolismo respiratório dos frutos, sendo muito importantes do ponto de vista do sabor e odor. Os ácidos orgânicos encontrados em pêssegos e nectarinas são principalmente succínico, tartárico, xiquímico, málico e cítrico, com predominância dos dois últimos (COSTA et al., 2008).

Quanto à relação sólidos solúveis/acidez titulável (SS/AT), verificaram-se maiores valores na seleção Cascata 587 e na cultivar CP-9553 CYN (Tabela 3). De acordo com Costa et al. (2008), a relação SS/AT é indicativa do nível de amadurecimento do fruto fresco e, de modo geral, essa relação em pêssegos pode variar de 16,5 até 36,0 , sendo que um valor de 25 ou acima equivale à maturidade ótima comestível, ou seja, à do fruto macio, se a acidez/ titulável for inferior a $0,5 \%$. De acordo com Almeida e Durigan (2006), a aquisição da fruta baseada nos valores dessa relação seria o melhor atributo para a valorização do produto no mercado atacadista do Estado de São Paulo.

$\mathrm{O} \mathrm{pH}$ apresentou pouca variação entre as cultivares e seleções avaliadas, variando de 3,3 (Turmalina e Cascata 968) a 3,8 (Cascata 848, Cascata 587, Diamante Mejorado e Oro Azteca) (Tabela 5). Chitarra e Chitarra (2005) relataram que o $\mathrm{pH}$ de pessegueiros pode variar de 3,5 a 4,8. De acordo com os resultados obtidos por Barbosa et al. (1997), o pH variou de 4,0 a 4,5 para vinte e dois pessegueiros e de 3,6 a 4,5 para treze nectarineiras, do germoplasma da Estação Experimental de Jundiaí do IAC, sendo cultivares e seleções introduzidas da Universidade da Flórida, Gainesville, EUA. A nectarineira 'Sun Blaze', avaliada neste ensaio, apresentou valores de $\mathrm{pH}$ de 3,4,3,4, e 3,7, respectivamente, nos anos de 2006, 2007 e 2008 . 


\begin{tabular}{|c|c|c|}
\hline - -Temp. mínima & ー—Temp. máxima & $\rightarrow$ *Temp. média \\
\hline —-Precipitação pluvial & $\rightarrow$-Umidade Relativa & \\
\hline
\end{tabular}
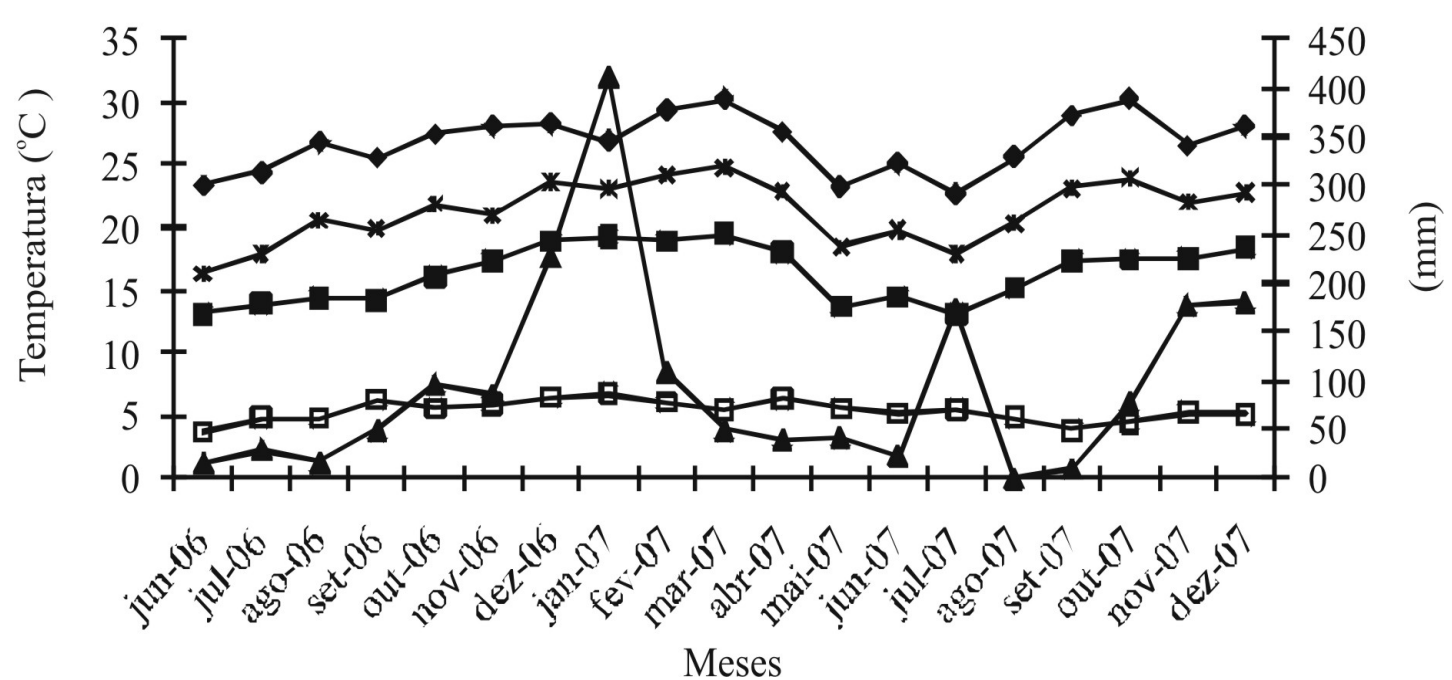

Meses

\begin{tabular}{|lll|}
\hline -Temp. mínima & $\rightarrow$ Temp. máxima & *-Temp. média \\
$\rightarrow$-Precipitação pluvial & $\rightarrow$ \&Umidade Relativa & \\
\hline
\end{tabular}

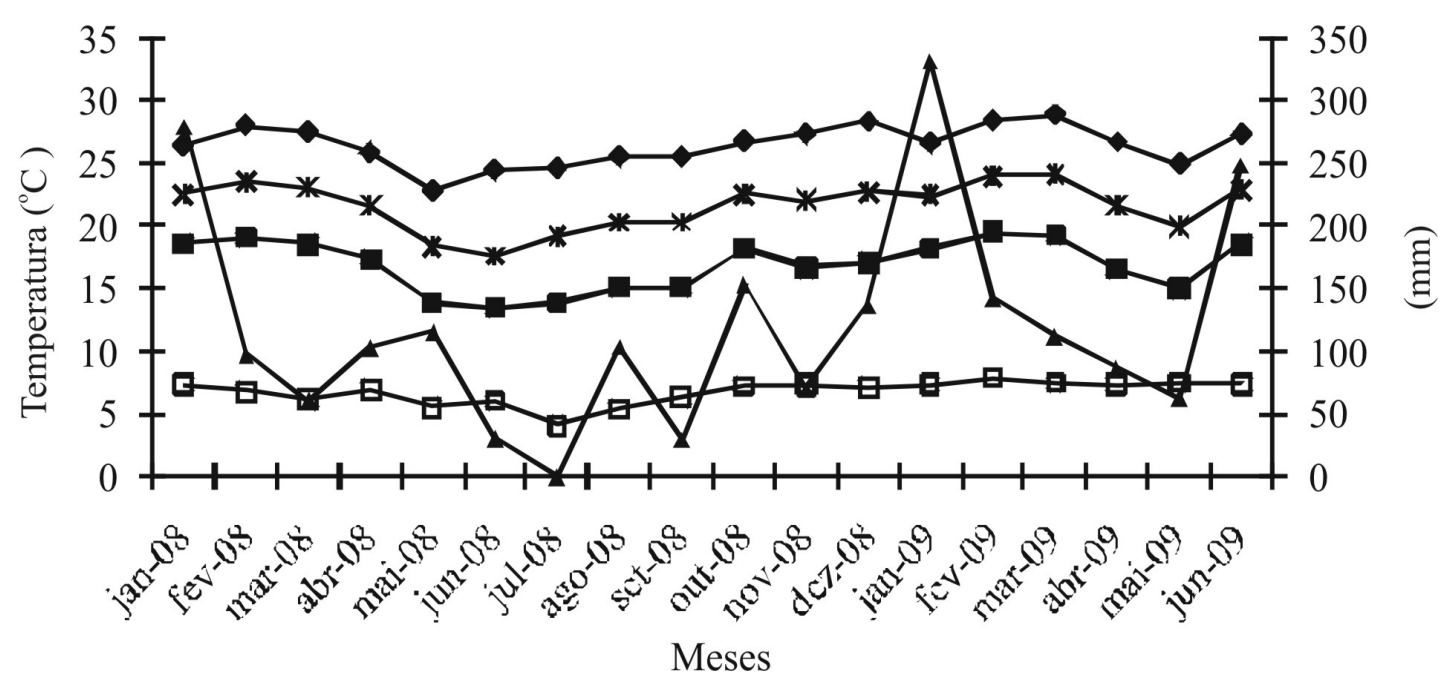

FIGURA 1-Temperaturas mínima, média, máxima, umidade relativa do ar e precipitação pluvial mensal acumulada no período de junho 2006 a dezembro de 2007 e de janeiro de 2008 a junho de 2009. Botucatu-SP. 
TABELA 1 - Produtividade, diâmetros longitudinal e transversal de frutos de cultivares de pessegueiro e nectarineira, nos ciclos de produção de 2006, 2007 e 2008.

\begin{tabular}{|c|c|c|c|c|}
\hline \multirow[b]{2}{*}{ Cultivares } & Ano 2006 & Ano 2007 & Ano 2008 & Média \\
\hline & \multicolumn{4}{|c|}{ Produtividade $\left(\mathrm{kg} \mathrm{ha}^{-1}\right)$} \\
\hline Turmalina & $3719 \mathrm{Aa}$ & $2767 \mathrm{Ab}$ & $4262 \mathrm{Aa}$ & $3583 \mathrm{~A}$ \\
\hline Cascata 968 & $1037 \mathrm{Ba}$ & $994 \mathrm{Da}$ & $1346 \mathrm{Ea}$ & $1126 \mathrm{~F}$ \\
\hline Cascata 848 & $2127 \mathrm{Bb}$ & $2404 \mathrm{ABab}$ & $3105 \mathrm{ABCa}$ & $2545 \mathrm{~B}$ \\
\hline Cascata 587 & $1097 \mathrm{Bb}$ & $1614 \mathrm{ABCDb}$ & $2487 \mathrm{CDEa}$ & $1733 \mathrm{CDEF}$ \\
\hline Conserva 693 & $2043 \mathrm{Bb}$ & $2363 \mathrm{ABCab}$ & $2979 \mathrm{BCa}$ & $2462 \mathrm{BC}$ \\
\hline Precocinho & $1183 \mathrm{Bb}$ & $1500 \mathrm{BCDab}$ & $2117 \mathrm{CDEa}$ & $1600 \mathrm{DEF}$ \\
\hline Diamante Mejorado & $1002 \mathrm{Bb}$ & $1185 \mathrm{CDb}$ & $2953 \mathrm{BCDa}$ & $1714 \mathrm{CDEF}$ \\
\hline Oro Azteca & $1181 \mathrm{Bb}$ & $2243 \mathrm{ABCa}$ & 1777 DEab & $1734 \mathrm{CDEF}$ \\
\hline CP CYN & $1159 \mathrm{Ba}$ & $1413 \mathrm{BCDa}$ & $1304 \mathrm{Ea}$ & $1292 \mathrm{EF}$ \\
\hline Tropic Beauty & $997 \mathrm{Bb}$ & $1192 \mathrm{CDb}$ & $3737 \mathrm{ABa}$ & $1975 \mathrm{BCDE}$ \\
\hline Sun Blaze & $1210 \mathrm{Bb}$ & $1362 \mathrm{BCDb}$ & $4001 \mathrm{ABa}$ & $2191 \mathrm{BCD}$ \\
\hline Média & $1523 \mathrm{~b}$ & $1731 \mathrm{~b}$ & $2733 \mathrm{a}$ & \\
\hline \multirow[t]{2}{*}{$\mathrm{CV}(\%)$ cultivar } & 23,1 & $\mathrm{CV}(\%)$ ano & 21,5 & \\
\hline & \multicolumn{4}{|c|}{ Diâmetro Longitudinal do fruto $(\mathrm{cm})$} \\
\hline Turmalina & $6,7 \mathrm{ABa}$ & $7,1 \mathrm{ABCa}$ & $7,1 \mathrm{Aa}$ & $7,0 \mathrm{AB}$ \\
\hline Cascata 968 & 5,6 $\mathrm{ABCa}$ & $5,5 \mathrm{Da}$ & $5,7 \mathrm{ABa}$ & $5,6 \mathrm{DE}$ \\
\hline Cascata 848 & $5,1 \mathrm{Ca}$ & $5,0 \mathrm{Da}$ & $5,0 \mathrm{Ba}$ & $5,0 \mathrm{E}$ \\
\hline Cascata 587 & $7,0 \mathrm{Aa}$ & $7,7 \mathrm{Aa}$ & $6,7 \mathrm{Aa}$ & $7,1 \mathrm{~A}$ \\
\hline Conserva 693 & $6,2 \mathrm{ABCa}$ & $5,8 \mathrm{CDa}$ & $5,8 \mathrm{ABa}$ & $5,9 \mathrm{CDE}$ \\
\hline Precocinho & $5,9 \mathrm{ABCa}$ & $5,9 \mathrm{CDa}$ & $5,9 \mathrm{ABa}$ & $5,9 \mathrm{DE}$ \\
\hline Diamante Mejorado & $6,0 \mathrm{ABCa}$ & $5,3 \mathrm{Da}$ & $5,7 \mathrm{ABa}$ & $5,7 \mathrm{DE}$ \\
\hline Oro Azteca & $6,0 \mathrm{ABCa}$ & $6,0 \mathrm{BCDa}$ & $6,2 \mathrm{ABa}$ & $6,1 \mathrm{BCD}$ \\
\hline CP CYN & $5,3 \mathrm{BCa}$ & $6,0 \mathrm{BCDa}$ & $6,1 \mathrm{ABa}$ & $5,8 \mathrm{DE}$ \\
\hline Tropic Beauty & $6,6 \mathrm{ABCa}$ & $7,5 \mathrm{ABa}$ & $6,8 \mathrm{Aa}$ & $7,0 \mathrm{AB}$ \\
\hline Sun Blaze & $5,5 \mathrm{ABCb}$ & $8,0 \mathrm{Aa}$ & 7,0 Aa & $6,8 \mathrm{ABC}$ \\
\hline Média & $6,0 \mathrm{a}$ & $6,3 \mathrm{a}$ & $6,2 \mathrm{a}$ & \\
\hline \multirow[t]{2}{*}{ CV $(\%)$ cultivar } & 9,1 & $\mathrm{CV}(\%)$ ano & 9,9 & \\
\hline & \multicolumn{4}{|c|}{ DiâmetroTransversal do fruto $(\mathrm{cm})$} \\
\hline Turmalina & $6,1 \mathrm{Ab}$ & $7,8 \mathrm{Aa}$ & $6,9 \mathrm{Aab}$ & $6,9 \mathrm{~A}$ \\
\hline Cascata 968 & $5,6 \mathrm{Aa}$ & $5,5 \mathrm{BCa}$ & $5,6 \mathrm{ABCa}$ & $5,5 \mathrm{~B}$ \\
\hline Cascata 848 & $5,0 \mathrm{Aa}$ & $5,3 \mathrm{BCa}$ & $5,1 \mathrm{Ca}$ & $5,1 \mathrm{~B}$ \\
\hline Cascata 587 & $6,3 \mathrm{Ab}$ & 7,5 Aa & $6,4 \mathrm{ABCb}$ & $6,7 \mathrm{~A}$ \\
\hline Conserva 693 & $6,1 \mathrm{Aa}$ & $5,4 \mathrm{BCa}$ & $5,4 \mathrm{BCa}$ & $5,6 \mathrm{~B}$ \\
\hline Precocinho & $5,8 \mathrm{Aa}$ & $5,5 \mathrm{BCa}$ & $5,5 \mathrm{BCa}$ & $5,6 \mathrm{~B}$ \\
\hline Diamante Mejorado & $5,7 \mathrm{Aa}$ & $4,4 \mathrm{Cb}$ & $5,5 \mathrm{BCa}$ & $5,2 \mathrm{~B}$ \\
\hline Oro Azteca & $5,8 \mathrm{Aa}$ & $5,6 \mathrm{BCa}$ & $5,8 \mathrm{ABCa}$ & $5,7 \mathrm{~B}$ \\
\hline CP CYN & $5,1 \mathrm{Aa}$ & $5,9 \mathrm{Ba}$ & $5,9 \mathrm{ABCa}$ & $5,6 \mathrm{~B}$ \\
\hline Tropic Beauty & $6,0 \mathrm{Ab}$ & 7,8 Aa & $6,6 \mathrm{ABb}$ & $6,8 \mathrm{~A}$ \\
\hline Sun Blaze & $5,4 \mathrm{Ac}$ & $8,2 \mathrm{Aa}$ & $6,9 \mathrm{Ab}$ & $6,8 \mathrm{~A}$ \\
\hline Média & $5,7 \mathrm{~b}$ & $6,2 \mathrm{a}$ & $6,0 \mathrm{ab}$ & \\
\hline $\mathrm{CV}(\%)$ cultivar & 8,2 & $\mathrm{CV}(\%)$ ano & 8,7 & \\
\hline
\end{tabular}

Médias seguidas pela mesma letra em maiúsculo na coluna e minúsculo na linha não diferem entre si, pelo teste Tukey, a 5\%. 
TABELA 2 - Firmeza, teor de sólidos solúveis e acidez titulável de frutos de cultivares de pessegueiro e nectarineira, nos ciclos de produção de 2006, 2007 e 2008.

\begin{tabular}{|c|c|c|c|c|}
\hline & Ano 2006 & Ano 2007 & Ano 2008 & Média \\
\hline Cultivares & \multicolumn{4}{|c|}{ Firmeza $\left(\mathrm{gf} \mathrm{cm}^{-2}\right)$} \\
\hline Turmalina & $261,4 \mathrm{ABCa}$ & $242,5 \mathrm{ABCa}$ & $303,8 \mathrm{ABa}$ & $269,3 \mathrm{AB}$ \\
\hline Cascata 968 & $277,9 \mathrm{ABa}$ & $323,9 \mathrm{ABa}$ & $277,0 \mathrm{ABa}$ & $293,0 \mathrm{~A}$ \\
\hline Cascata 848 & $248,1 \mathrm{ABCb}$ & $173,4 \mathrm{Cb}$ & $379,0 \mathrm{Aa}$ & $266,8 \mathrm{AB}$ \\
\hline Cascata 587 & $155,6 \mathrm{Cb}$ & $170,9 \mathrm{Cb}$ & $319,3 \mathrm{ABa}$ & $215,3 \mathrm{~B}$ \\
\hline Conserva 693 & $220,5 \mathrm{ABCa}$ & $237,1 \mathrm{ABCa}$ & $296,0 \mathrm{ABa}$ & $251,2 \mathrm{AB}$ \\
\hline Precocinho & $168,3 \mathrm{BCb}$ & $214,9 \mathrm{BCab}$ & $265,7 \mathrm{ABa}$ & $216,3 \mathrm{~B}$ \\
\hline Diamante Mejorado & $292,4 \mathrm{Aa}$ & $231,7 \mathrm{ABCa}$ & $297,0 \mathrm{ABa}$ & $273,7 \mathrm{AB}$ \\
\hline Oro Azteca & $266,7 \mathrm{ABCa}$ & $256,2 \mathrm{ABCa}$ & $274,8 \mathrm{ABa}$ & $265,9 \mathrm{AB}$ \\
\hline CP 9553 CYN & $284,5 \mathrm{Aa}$ & $236,2 \mathrm{ABCa}$ & $278,0 \mathrm{ABa}$ & $266,2 \mathrm{AB}$ \\
\hline Tropic Beauty & $283,4 \mathrm{Aab}$ & $345,8 \mathrm{Aa}$ & $217,1 \mathrm{Bb}$ & $282,1 \mathrm{AB}$ \\
\hline Sun Blaze & $192,7 \mathrm{ABCb}$ & $327,0 \mathrm{ABa}$ & $263,1 \mathrm{Bab}$ & $260,9 \mathrm{AB}$ \\
\hline Média & $241,0 \mathrm{~b}$ & $250,9 \mathrm{~b}$ & $288,3 \mathrm{a}$ & \\
\hline \multirow[t]{2}{*}{ CV $(\%)$ cultivar } & 15,8 & CV $(\%)$ ano & 16,4 & \\
\hline & \multicolumn{4}{|c|}{ Teor de sólidos solúveis $\left({ }^{\circ}\right.$ Brix $)$} \\
\hline Turmalina & $11,8 \mathrm{ABa}$ & $11,1 \mathrm{Ca}$ & $11,9 \mathrm{ABa}$ & $11,6 \mathrm{~B}$ \\
\hline Cascata 968 & $13,5 \mathrm{Aab}$ & $14,8 \mathrm{ABa}$ & $12,4 \mathrm{ABb}$ & $13,6 \mathrm{~A}$ \\
\hline Cascata 848 & $12,1 \mathrm{ABa}$ & $11,4 \mathrm{Ca}$ & $12,2 \mathrm{ABa}$ & $11,9 \mathrm{~B}$ \\
\hline Cascata 587 & $11,9 \mathrm{ABa}$ & $11,3 \mathrm{Ca}$ & $11,6 \mathrm{Ba}$ & $11,6 \mathrm{~B}$ \\
\hline Conserva 693 & $11,7 \mathrm{ABa}$ & $12,4 \mathrm{Ca}$ & $11,2 \mathrm{Ba}$ & $11,8 \mathrm{~B}$ \\
\hline Precocinho & $11,3 \mathrm{ABa}$ & $12,9 \mathrm{ABCa}$ & $11,6 \mathrm{Ba}$ & $11,9 \mathrm{~B}$ \\
\hline Diamante Mejorado & $12,1 \mathrm{ABb}$ & $14,9 \mathrm{Aa}$ & $11,0 \mathrm{Bb}$ & $12,7 \mathrm{AB}$ \\
\hline Oro Azteca & $11,8 \mathrm{ABa}$ & $11,3 \mathrm{Ca}$ & $11,3 \mathrm{Ba}$ & $11,5 \mathrm{~B}$ \\
\hline CP 9553 CYN & $10,4 \mathrm{Bb}$ & $12,6 \mathrm{BCa}$ & $12,4 \mathrm{ABa}$ & $11,8 \mathrm{~B}$ \\
\hline Tropic Beauty & $11,2 \mathrm{Bb}$ & $11,0 \mathrm{Cb}$ & $14,1 \mathrm{Aa}$ & $12,1 \mathrm{~B}$ \\
\hline Sun Blaze & $11,3 \mathrm{ABa}$ & $12,3 \mathrm{Ca}$ & $11,3 \mathrm{Ba}$ & $11,6 \mathrm{~B}$ \\
\hline Média & $11,7 \mathrm{~b}$ & $12,4 \mathrm{a}$ & $11,9 \mathrm{ab}$ & \\
\hline \multirow[t]{2}{*}{ CV $(\%)$ cultivar } & 7,2 & $\mathrm{CV}(\%)$ ano & 7,1 & \\
\hline & \multicolumn{4}{|c|}{ Acidez titulável (g ácido cítrico $100 \mathrm{~g}$ de polpa ${ }^{-1}$ ) } \\
\hline Turmalina & $0,75 \mathrm{ABa}$ & $0,72 \mathrm{DEFa}$ & $0,74 \mathrm{ABCa}$ & $0,74 \mathrm{BC}$ \\
\hline Cascata 968 & $0,95 \mathrm{Ab}$ & $1,16 \mathrm{Aa}$ & $0,79 \mathrm{ABb}$ & $0,97 \mathrm{~A}$ \\
\hline Cascata 848 & $0,81 \mathrm{ABa}$ & $0,57 \mathrm{FGb}$ & $0,83 \mathrm{ABa}$ & $0,74 \mathrm{BC}$ \\
\hline Cascata 587 & $0,41 \mathrm{Ca}$ & $0,41 \mathrm{Ga}$ & 0,59 BCDEa & $0,47 \mathrm{E}$ \\
\hline Conserva 693 & $0,83 \mathrm{ABa}$ & 0,86 BCDEa & $0,85 \mathrm{Aa}$ & $0,85 \mathrm{AB}$ \\
\hline Precocinho & $0,62 \mathrm{BCab}$ & $0,80 \mathrm{CDEFa}$ & $0,46 \mathrm{DEb}$ & $0,62 \mathrm{CD}$ \\
\hline Diamante Mejorado & $0,84 \mathrm{ABb}$ & $1,07 \mathrm{ABa}$ & $0,40 \mathrm{Ec}$ & $0,77 \mathrm{BC}$ \\
\hline Oro Azteca & $0,74 \mathrm{ABa}$ & $0,62 \mathrm{EFGa}$ & 0,69 ABCDa & $0,68 \mathrm{CD}$ \\
\hline CP 9553 CYN & $0,42 \mathrm{Cb}$ & $0,76 \mathrm{CDEFa}$ & $0,52 \mathrm{CDEb}$ & $0,57 \mathrm{DE}$ \\
\hline Tropic Beauty & $1,00 \mathrm{Aa}$ & $0,90 \mathrm{ABCDab}$ & $0,75 \mathrm{ABCb}$ & $0,88 \mathrm{AB}$ \\
\hline Sun Blaze & $0,88 \mathrm{Aab}$ & $1,01 \mathrm{ABCa}$ & $0,71 \mathrm{ABCDb}$ & $0,87 \mathrm{AB}$ \\
\hline Média & $0,8 \mathrm{a}$ & $0,8 \mathrm{a}$ & $0,7 \mathrm{~b}$ & \\
\hline CV $(\%)$ cultivar & 12,0 & $\mathrm{CV}(\%)$ ano & 13,4 & \\
\hline
\end{tabular}

Médias seguidas pela mesma letra em maiúsculo na coluna e minúsculo na linha não diferem entre si, pelo teste Tukey, a $5 \%$. 
TABELA 3 - pH, açúcares redutores e relação entre sólidos solúveis e acidez titulável (SS/AT) de frutos de cultivares de pessegueiro e nectarineira, nos ciclos de produção de 2006, 2007 e 2008.

\begin{tabular}{ccccc}
\hline & Ano 2006 & Ano 2007 & Ano 2008 & Média \\
\cline { 2 - 5 } Cultivares & & \multicolumn{3}{c}{ SS/AT } \\
\hline Turmalina & $15,8 \mathrm{Ca}$ & $15,5 \mathrm{Ba}$ & $16,0 \mathrm{BCDa}$ & $15,8 \mathrm{CDE}$ \\
Cascata 968 & $14,4 \mathrm{Ca}$ & $12,3 \mathrm{Ba}$ & $15,8 \mathrm{BCDa}$ & $14,2 \mathrm{DE}$ \\
Cascata 848 & $15,0 \mathrm{Ca}$ & $20,1 \mathrm{ABa}$ & $14,8 \mathrm{CDa}$ & $16,6 \mathrm{CDE}$ \\
Cascata 587 & $30,7 \mathrm{Aa}$ & $29,0 \mathrm{Aa}$ & $21,0 \mathrm{ABCDb}$ & $26,9 \mathrm{~A}$ \\
Conserva 693 & $14,2 \mathrm{Ca}$ & $14,4 \mathrm{Ba}$ & $13,1 \mathrm{Da}$ & $13,9 \mathrm{DE}$ \\
Precocinho & $18,2 \mathrm{BCab}$ & $16,5 \mathrm{Bb}$ & $25,5 \mathrm{ABa}$ & $20,1 \mathrm{BC}$ \\
Diamante Mejorado & $14,4 \mathrm{Cb}$ & $13,9 \mathrm{Bb}$ & $27,6 \mathrm{Aa}$ & $18,6 \mathrm{BCD}$ \\
Oro Azteca & $16,3 \mathrm{BCa}$ & $18,1 \mathrm{Ba}$ & $17,8 \mathrm{ABCDa}$ & $17,4 \mathrm{CDE}$ \\
CP 9553 CYN & $26,5 \mathrm{ABa}$ & $16,6 \mathrm{Bb}$ & $25,1 \mathrm{ABCa}$ & $22,8 \mathrm{AB}$ \\
Tropic Beauty & $11,2 \mathrm{Cb}$ & $12,3 \mathrm{Bab}$ & $19,6 \mathrm{ABCDa}$ & $14,4 \mathrm{DE}$ \\
Sun Blaze & $12,9 \mathrm{Ca}$ & $12,2 \mathrm{Ba}$ & $15,9 \mathrm{BCDa}$ & $13,7 \mathrm{E}$ \\
\hline Média & $17,2 \mathrm{ab}$ & $16,4 \mathrm{~b}$ & $19,3 \mathrm{a}$ & \\
CV $(\%)$ cultivar & 16,6 & $\mathrm{CV}(\%)$ ano & 23,7 & \\
\hline
\end{tabular}

Médias seguidas pela mesma letra em maiúsculo na coluna e minúsculo na linha não diferem entre si, pelo teste Tukey, a $5 \%$.

TABELA 4 - Açúcares solúveis totais de frutos de cultivares de pessegueiro e nectarineira, nos ciclos de produção de 2006, 2007 e 2008.

\begin{tabular}{cc}
\hline ANO & Açúcares solúveis totais (\%) \\
\hline 2006 & $7,9 \mathrm{~B}$ \\
2007 & $8,9 \mathrm{~A}$ \\
2008 & $6,8 \mathrm{C}$ \\
\hline Média & 7,9 \\
CV (\%) & 23,7 \\
\hline
\end{tabular}

Médias seguidas pela mesma letra em maiúsculo não diferem entre si, pelo teste Tukey, a 5\%.

\section{CONCLUSÕES}

1 - A cultivar de pessegueiro Turmalina é a mais produtiva, em relação às demais cultivares avaliadas.

2 - A seleção de pessegueiro Cascata 968 e a cultivar Diamante Mejorado apresentam o maior teor de sólidos solúveis, e as cultivares Cascata 587 e CP 9553 CYN apresentam a maior relação sólidos solúveis/acidez titulável.

\section{AGRADECIMENTOS}

À Dra. Maria do Carmo Bassols Raseira (EMBRAPA-CPACT) e ao Prof. Dr. Gilmar Arduíno Bettio Marodin (UFRGS), pela permissão para a avaliação dos genótipos em Botucatu-SP. Aos irmãos Kagi, pela doação das mudas.

\section{REFERÊNCIAS}

ALMEIDA, G.B.V.; DURIGAN, J.F. Relação entre as características químicas e o valor dos pêssegos comercializados pelo sistema veiling frutas Holambra em Paranapanema-SP. Revista Brasileira de Fruticultura, Jaboticabal, v. 28, p. 218-221, 2006.

ANUÁRIO BRASILEIRO DA FRUTICULTURA 2010. Santa Cruz do Sul: Editora Gazeta Santa Cruz do Sul, 2010. 128 p.

BALDWIN, E.A. Flavor. Winter Haven: Citrus and Subtropical Products Laboratory. Disponível em: <http://www.ars.usda.gov/pandp/people. htm?personid=263>. Acesso em: 03 jun. 2005. 
BARBOSA, W.; CHAGAS, E.A.; POMMER, C.V.; PIO, R. Advances in low-chilling peach breading at Instituto Agronômico, São Paulo State, Brazil. IN: INTERNATIONAL SYMPOSIUM OF TEMPERATES ZONE FRUITS IN THE TROPICS AND SUBTROPICS, 8., 2007.Florianópolis. Proceedings... Pelotas: Embrapa Clima Temperado, 2007. p. $30-31$.

BARBOSA, W.; OJIMA, M.; DALL'ORTO, F.A.C. Comportamento do pessegueiro 'Douradão' em Itupeva. Scientia Agrícola, Piracicaba, v. 56, p. 1261-1265, 1999.

BARBOSA, W.; OJIMA, M.; DALL'ORTO, F.P.; MARTINS, J.L.; CASTRO, J.L.; SANTOS, R.R. Avaliação de pessegueiros e nectarineiras introduzidos no Brasil, procedentes da flórida, EUA. Scientia Agrícola, Piracicaba, v. 54, p. 152-159, 1997.

BARBOSA, W.; POMMER, C. V.; RIBEIRO, M. D.; VEIGA, R. F. de A.; COSTA, A. A Distribuição geográfica e diversidade varietal de frutíferas e nozes de clima temperado no Estado de São Paulo. Revista Brasileira de Fruticultura, Jaboticabal, v. 25, p. 341-344, 2003.

CHITARRA, M.I.F.; CARVALHO, V.D. Frutos temperados; pêssegos, ameixas e figos. Informe Agropecuário, Belo Horizonte, v. 11, p. 56-66, 1985.

CHITARRA, M.I.F.; CHITARRA, A.B. Pós-colheita de frutas e hortaliças: fisiologia e manuseio. Lavras: UFLA, 2005. $785 \mathrm{p}$.

COSTA, S.M.; MANOEL, L.; MOREIRA, G.C.; VIEITES, R.L.; LIMA, L.C.; PALAMIN, M.L. Conservação frigorificada de pêssegos 'Tropic Beauty' irradiados. Revista Iberoamericana de Tecnologia Postcosecha, Toluca, v. 9, p. 131-137, 2008.

CUNHA, A.R.; KLOSOWSKI, E.S.; GALVANI, E.; SCOBEDO, J.F.; MARTINS, D. Classificação climática para o município de Botucatu-SP, segundo Köeppen. In: SIMPÓSIO EM ENERGIA NAAGRICULTURA, 1., 1999, Botucatu. Anais... Botucatu: Faculdade de Ciências Agronômicas, Universidade Estadual Paulista, 1999. p.487-491.

EMBRAPA. Centro Nacional de Pesquisa de Solos. Sistema brasileiro de classificação de solos. Rio de Janeiro, 1999. 412 p.

ESTI, M.; DESPHANDE, P.B.; SALUNKE, D.K. Effect of maturity and storage on certain biochemical changes in apricot and peaches. Food Chemistry, Reading, v. 60, p. 659-666, 1997.
GONÇALVES, N.B. Efeito da aplicação de cloreto de cálcio associado ao tratamento hidrotérmico sobre a composição química e sustentabilidade ao escurecimento interno do abacaxi cv Smooth Cayenne. 1998. 101 f. Tese (Doutorado) - Universidade Federal de Lavras, Lavras, 1988.

INSTITUTO ADOLFO LUTZ. Normas analíticas: métodos químicos e físicos para a análise de alimentos. 2.ed. São Paulo: 1985. v. 1, 371 p.

MARODIN, G.A.B.; PEREIRA DIAS, F.; CASTRO, B.; ARGENTA, F. Comportamento de algumas cultivares de pêssegos na depressão central do Rio Grande do Sul In: CONGRESSO BRASILEIRO DE FRUTICULTURA, 20., 2007, Vitória. Anais... Vitória: SBF, 2008. p. 25-30.

NAKASU, B.H.; RASEIRA, M.C.B. Turmalina: uma cultivar de pêssego para uso industrial. Ciência e Agrotecnologia, Lavras, v. 23, p. 234-236, 1999.

NELSON, N. Aphotometric adaptation of Somogy method for determination of glicose. The Journal of Biological Chemistry, Maryland, v. 153, p. $375-$ 380,1944 .

OLIVEIRA, M.A.; CEREDA, M.P.; CABELLO, C.; URBANO, L.H. Quantificação de açúcares em pêssegos da variedade Biuti, armazenados sob condições de ambiente e refrigeração, Revista Brasileira de Fruticultura, Jaboticabal, v. 23, p. 424-427, 2001.

PEREIRA, F.M.; NATCHIGAL, J.C.; ROBERTO, S.R. Tecnologia para a cultura do pessegueiro em regiões subtropicais. Jaboticabal: FUNEP, 2002. 62 p.

PINTO, L.C.B.; JORGE, J.T. Utilização de 1-metilciclorpopeno e resfriamento rápido na conservação de pêssegos. Revista Engenharia Agrícola, Jaboticabal, v. 27, p. 238-246, 2007.

RASEIRA, M. C. B.; NAKASU, B. H. Cultivares: descrição e recomendação. In: MEDEIROS, C. A. B.; RASEIRA, M. do C.B. (Ed.). A cultura do pessegueiro. Brasília : EMBRAPA, SPI; Pelotas: EMBRAPA, CPACT, 1998. p. 29-97.

RASEIRA, M.C.B.; NAKASU, B.H.; PEREIRA, J.F.M. Seleções avançadas de pessegueiros produtoras de frutos para mesa. In: CONGRESSO BRASILEIRO DE FRUTICULTURA, 20., 2007, Vitória. Anais... Vitória: SBF, 2007. p. 43, 2007.

SCARPARE FILHO, J.A.; KLUGE, R.A.; TAVARES, S. A cultura do pessegueiro: recomendações para o cultivo em regiões subtropicais. Piracicaba: ESALQ, 2003. 48 p. (Série Produtor Rural, 21). 